\title{
Could Total Neoadjuvant Therapy Followed by Surgical Resection Be the New Standard of Care in Pancreatic Cancer? A Systematic Review and Meta-Analysis
}

\author{
Ottavia De Simoni ${ }^{1}\left(\mathbb{D}\right.$, Marco Scarpa $^{2} \mathbb{D}$, Caterina Soldà ${ }^{3}$, Francesca Bergamo ${ }^{3}$, Sara Lonardi ${ }^{4}$ (D), Alberto Fantin ${ }^{5}$, \\ Pierluigi Pilati ${ }^{1}$ and Mario Gruppo ${ }^{1, * \mathbb{D}}$
}

check for

updates

Citation: De Simoni, O.; Scarpa, M.; Soldà, C.; Bergamo, F.; Lonardi, S.;

Fantin, A.; Pilati, P.; Gruppo, M. Could Total Neoadjuvant Therapy Followed by Surgical Resection Be the New Standard of Care in

Pancreatic Cancer? A Systematic Review and Meta-Analysis. J. Clin. Med. 2022, 11, 812. https://doi.org/ $10.3390 /$ jcm11030812

Academic Editor: David Fuks

Received: 24 December 2021

Accepted: 31 January 2022

Published: 3 February 2022

Publisher's Note: MDPI stays neutral with regard to jurisdictional claims in published maps and institutional affiliations.

Copyright: (C) 2022 by the authors. Licensee MDPI, Basel, Switzerland. This article is an open access article distributed under the terms and conditions of the Creative Commons Attribution (CC BY) license (https:// creativecommons.org/licenses/by/ $4.0 /)$
1 Unit of Surgical Oncology of Digestive Tract, Veneto Institute of Oncology IOV-IRCCS, 35128 Padua, Italy; ottavia.desimoni@iov.veneto.it (O.D.S.); pierluigi.pilati@iov.veneto.it (P.P.)

2 Department of Surgery, Oncology and Gastroenterology, University Hospital of Padua, 35128 Padova, Italy; marcoscarpa73@yahoo.it

3 Unit of Medical Oncology 1, Veneto Institute of Oncology IOV-IRCCS, 35128 Padua, Italy; caterina.solda@iov.veneto.it (C.S.); francesca.bergamo@iov.veneto.it (F.B.)

4 Unit of Medical Oncology 3, Veneto Institute of Oncology IOV-IRCCS, 35128 Padua, Italy; sara.lonardi@iov.veneto.it

5 Department of Gastroenterology, Veneto Institute of Oncology IOV-IRCCS, 35128 Padua, Italy; alberto.fantin@iov.veneto.it

* Correspondence: mario.gruppo@iov.veneto.it; Tel.: +390423421306

\begin{abstract}
Background. Total neoadjuvant therapy (TNT), intended as induction chemotherapy (IC) followed by radio-chemotherapy (RCT), has been taking hold in the treatment of pancreatic ductal adenocarcinoma (PDAC). The aim of this review is to summarize the available evidence on the role of TNT followed by curative surgery. Methods. Eligible studies were those reporting on patients with PDAC undergoing curative surgery after TNT. The primary endpoint was overall survival (OS). Results. A total of 1080 patients with PDAC who had undergone TNT were analyzed. The most common IC regimen was Gemcitabine (N 620, 57\%). Toxicity during IC varied from $14 \%$ to $51 \%$. Disease progression during IC varied from 3\% to 25\%. 607 (62\%) patients underwent curative surgery after IC + CRT. In meta-analysis, the available data on lymph node metastases radicality and 2 years OS had better results in favor of TNT groups (OR 1.77, 95\% CI 1.20-2.60, $p=0.004$ and OR 2.03, $95 \%$ CI 1.19-3.47, $p=0.01$ and OR 1.64, CI 1.09-2.47, $p=0.02$, respectively). Conclusions. Despite the heterogeneity of the studies, different selection criteria, and non-negligible drop-out rate, TNT demonstrated a potential superiority to NAT without CRT in oncological and pathological outcomes, even if the main differences seem to depend on the IC regimen.
\end{abstract}

Keywords: total neoadjuvant therapy; pancreatic cancer; induction chemotherapy; radio-chemotherapy; pancreatectomy; pancreatic surgery; overall survival

\section{Introduction}

Pancreatic ductal adenocarcinoma (PDAC) is one of the leading causes of cancer mortality in developed countries and one of the most lethal malignant neoplasms across the world [1]. Surgical resection in combination with adjuvant systemic chemotherapy is still the standard of care with curative intent [2,3]. However, at diagnosis, only 15-20\% of patients are resectable and about $30 \%$ have locally advanced unresectable tumors and are generally given palliative measures only [4-6].

Neoadjuvant chemotherapy (NAT) is increasingly administered to borderline-resectable (BR) and locally advanced (LA) PDAC with the achievement of a higher percentage of resectability and improvement of oncological outcomes $[7,8]$. The concept of neoadjuvant rather than adjuvant treatment in PDAC is attractive for several reasons: downstaging of large tumors to allow margin negative resections, facilitate improved patient selection for 
resection by revealing biological aggressiveness, allow for further observation of indeterminate extrapancreatic lesions prior to resection, and enable medical optimization prior to surgery [9-12]. Second, up to $30 \%$ of the patients cannot receive adjuvant therapy because of poor post-operative performance status [13]. Recently, the concept of total neoadjuvant chemotherapy (TNT) benefiting from both the possible advantages of neoadjuvant therapy and radiotherapy is developing an increasing interest but is not widely accepted [14,15]. The purpose of this systematic review is to summarize the available evidence on the role of TNT followed by surgery with curative intent.

\section{Materials and Methods}

\subsection{Study Design}

We performed a systematic literature search, study design, and data analysis following PRISMA (Preferred Reporting Items for Systematic Reviews and Meta-Analyses) guidelines [16].

\subsection{Search Strategy}

Five medical databases were consulted in this research: Medline, Embase, Cochrane Database of Systematic Reviews, Web of Science, and Scopus. The primary search strategy included keywords and medical subject headings as follows: "Pancreatic cancer," "Pancreatic cancers," "Cancer of pancreas," "Cancer of the pancreas,," "Duct cell carcinoma of the pancreas," "Ductal carcinoma of the pancreas," "Total neoadjuvant chemotherapy," "Total neoadjuvant therapy," and "Total neoadjuvant treatment." Articles from the search results have been selected independently by two authors (M.G. and O.D.) following the inclusion and exclusion criteria. Any disagreements in study inclusion between the two authors were resolved by discussion. Only clinical studies written in English were selected. We did not include data quoted as unpublished or derived from abstracts.

\subsection{Selection Criteria and Outcome Measures}

We included all studies investigating a series of patients with a diagnosis of PDAC who underwent TNT followed by curative surgery. We considered TNT a protocol consisting of a phase of induction chemotherapy (IC) followed by a phase of radiotherapy with concurrent chemotherapy (CRT). For the purpose of this review, chemotherapy should be considered as "induction" if it is administered before radiotherapy and "concurrent" if administered during the course of radiotherapy. In the case of duplicate publications that reported on (parts of) similar patient data, only the most recent and complete data sets were considered. Exclusion criteria were as follows: $<15$ total patients. According to the PICOS criteria, articles were selected in this systematic review according to the follow eligibility criteria: (1) participants: adults with diagnosis of PDAC; (2) intervention: TNT followed by curative surgery; (3) comparison: patients with PDAC undergoing surgery first or neoadjuvant chemotherapy followed by surgery; (4) outcomes: the main outcome measure was overall survival (OS); secondary endpoints were tolerance to TNT, pathological and surgical outcomes, and disease-free survival (DFS).

\subsection{Data Extraction}

Data were extracted from original articles only using a set of predetermined parameters: demographic data, localization of cancer, histological details of PDAC, type of TNT, tolerance to TNT, type of surgery, morbidity, 90 days mortality, DFS, and OS.

\subsection{Quality Assessment of Retrieved Articles}

Two researchers independently assessed the quality of the articles using a quality evaluation list constructed with predefined parameters including: number of patients, accurate description of IC regimens, CRT regimen, surgical procedure, and accurate analysis of response and tolerance to IC + CRT. Moreover, the Newcastle-Ottawa Scale (NOS) was utilized for assessing the quality of non-randomized studies in systematic review analyses. 


\subsection{Statistical Analysis}

Review Manager 5.3 (Cochrane Collaboration, Nordic Cochrane Centre, Copenhagen, Denmark) was used for data analysis. All statistical measures were assessed with $p 0.05$ significance level. The $\mathrm{I}^{2}$ statistic was used to determine the heterogeneity of the included studies. Low, moderate, and high heterogeneity was considered for levels of $\mathrm{I}^{2}$ values of $25-49 \%, 50-74 \%$, and above 75\%, respectively [17]. We applied a random effects model, while if the $\mathrm{I}^{2}$ statistic was lower than $50 \%$, we applied a fixed-effect model to obtain pooled HR and 95\% CI. The graphical description of the statistical results was illustrated with a Forest plot.

\section{Results}

\subsection{Study Selection}

After the literature search, 2911 relevant non-duplicated records were identified; 2892 of them were excluded based on the title or the abstract because they covered a variety of irrelevant topics. Finally, 12 studies, published between 2012 and 2021, matched the selection criteria and were included in the quality analysis, as shown in Figure 1 [14,18-28]. The authors of potentially eligible studies with minor missing or incomplete data were directly contacted and invited to contribute additional information and data.

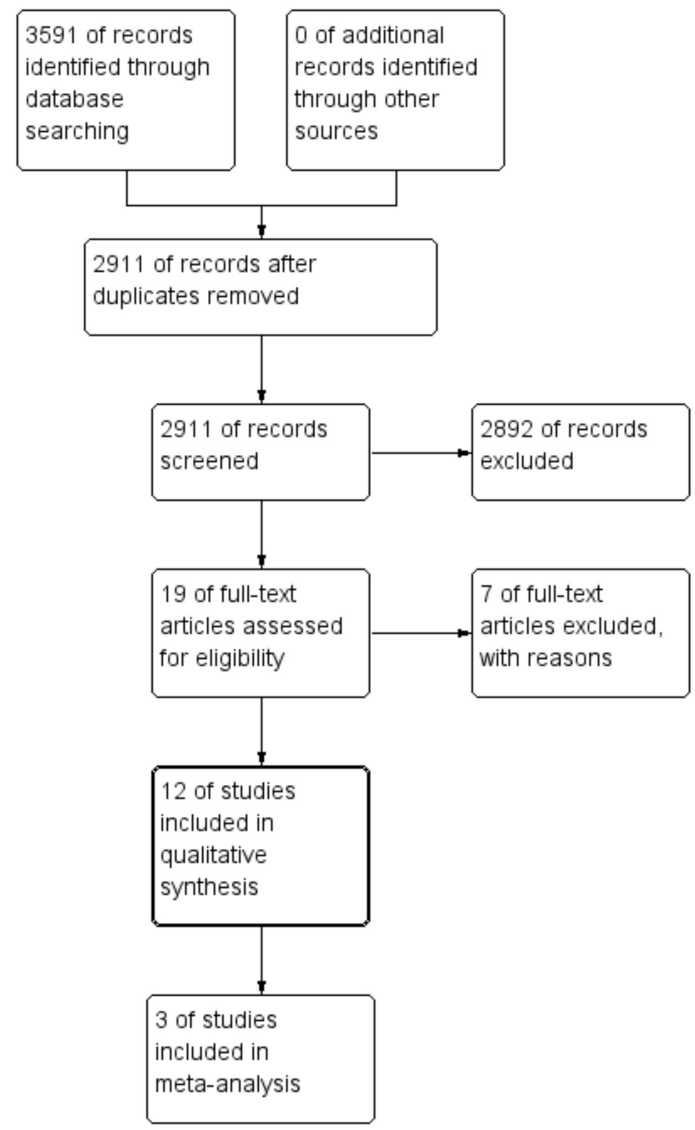

Figure 1. Flowchart of study selection.

\subsection{Study Characteristics and Patients Characteristics}

Twelve studies, all published between 2012 and 2021, matched the inclusion criteria and have been included in the qualitative analysis [14,18-28]. Five studies were prospective studies and seven were retrospective studies. The characteristics of the included studies are shown in Table 1. 
Table 1. Characteristics of studies analyzed.

\begin{tabular}{|c|c|c|c|c|c|c|}
\hline References & Publication Year & Centre & Country & Study Design & Inclusion Period & $\begin{array}{l}\text { No. of } \\
\text { Patients }\end{array}$ \\
\hline Kim et al. [18] & 2021 & Medical College of Wisconsin & USA & Retrospective & 2009-2019 & 89 \\
\hline Truty et al. [19] & 2021 & $\begin{array}{l}\text { Mayo Clinical College of } \\
\text { Medicine }\end{array}$ & USA & Retrospective & 2010-2017 & 254 \\
\hline Hayashi et al. [20] & 2019 & $\begin{array}{c}\text { Hokkaido Pancreas Study } \\
\text { Group (HOPS) }\end{array}$ & JAPAN & Prospective & 2013-2015 & 45 \\
\hline Murphy et al. [21] & 2019 & $\begin{array}{c}\text { Massachusetts General } \\
\text { Hospital }\end{array}$ & USA & Prospective & 2013-2018 & 49 \\
\hline Murphy et al. [22] & 2018 & $\begin{array}{c}\text { Massachusetts General } \\
\text { Hospital }\end{array}$ & USA & Prospective & 2012-2016 & 48 \\
\hline Takahashi et al. [23] & 2018 & $\begin{array}{c}\text { Osaka International Cancer } \\
\text { Institute }\end{array}$ & JAPAN & Prospective & Not specified & 38 \\
\hline Pietrasz et al. [14] & 2018 & Paul Brousse Hospital & FRANCE & Retrospective & 2010-2015 & 203 \\
\hline Grose et al. [24] & 2017 & $\begin{array}{c}\text { Beatson West of Scotland } \\
\text { Cancer Centre }\end{array}$ & UK & Retrospective & 2012-2015 & 85 \\
\hline Fiore et al. [25] & 2017 & $\begin{array}{l}\text { Campus Bio-Medico } \\
\text { University Rome }\end{array}$ & ITALY & Prospective & 2012-2015 & 41 \\
\hline Abbott et al. [26] & 2013 & $\begin{array}{l}\text { University of Cincinnati } \\
\text { School of Medicine }\end{array}$ & USA & Retrospective & Not specified & 164 \\
\hline Denost et al. [27] & 2012 & $\begin{array}{l}\text { University Hospital Centre } \\
\text { (CHU) Bordeaux }\end{array}$ & FRANCE & Retrospective & 2004-2009 & 111 \\
\hline Habermehl et al. [28] & 2012 & $\begin{array}{c}\text { University Hospital of } \\
\text { Heidelberg }\end{array}$ & GERMANY & Retrospective & 2001-2010 & 215 \\
\hline
\end{tabular}

All studies had a quality score $\geq 6$, assessed using the Newcastle-Ottawa score. All the studies reported an accurate description of IC and CTR. Five studies did not report the safety of and tolerance to chemotherapy $[14,18,20,26,27]$. The analysis of study quality has been summarized in Table 2.

Table 2. Level of evidence and quality assessment of the selected studies.

\begin{tabular}{|c|c|c|c|c|c|c|c|c|c|}
\hline \multirow{2}{*}{ References } & \multirow{2}{*}{$\begin{array}{c}\text { No. of } \\
\text { Patients }\end{array}$} & \multirow{2}{*}{$\begin{array}{l}\text { Accurate } \\
\text { Description } \\
\text { of IC }\end{array}$} & \multirow{2}{*}{$\begin{array}{l}\text { Accurate } \\
\text { Description } \\
\text { of CRT }\end{array}$} & \multirow{2}{*}{$\begin{array}{c}\text { Accurate } \\
\text { Description of Safety } \\
\text { and Tolerance to } \\
\text { IC + CRT }\end{array}$} & \multirow{2}{*}{$\begin{array}{c}\text { Accurate } \\
\text { Description of } \\
\text { Surgical } \\
\text { Procedure }\end{array}$} & \multicolumn{4}{|c|}{ Newcastle-Ottawa Score } \\
\hline & & & & & & Selection & Comparability & Outcome & Score \\
\hline $\begin{array}{l}\text { Kim et al., } \\
2021 \text { [18] }\end{array}$ & 89 & Yes & Yes & No & Yes & $* * * *$ & * & $* * *$ & 8 \\
\hline $\begin{array}{l}\text { Truty et al., } \\
2021 \text { [19] }\end{array}$ & 254 & Yes & Yes & Yes & Yes & $* * *$ & - & $* * *$ & 6 \\
\hline $\begin{array}{l}\text { Hayashi et al., } \\
2019 \text { [20] }\end{array}$ & 45 & Yes & Yes & No & Yes & $* * *$ & - & $* * *$ & 6 \\
\hline $\begin{array}{l}\text { Murphy et al., } \\
2019 \text { [21] }\end{array}$ & 49 & Yes & Yes & Yes & Yes & $* * *$ & - & $* * *$ & 6 \\
\hline $\begin{array}{l}\text { Murphy et al., } \\
2018 \text { [22] }\end{array}$ & 48 & Yes & Yes & Yes & Yes & $* * *$ & - & $* * *$ & 6 \\
\hline $\begin{array}{l}\text { Takahashi } \\
\text { et al., 2018 [23] }\end{array}$ & 38 & Yes & Yes & Yes & Yes & $* * *$ & - & $* * *$ & 6 \\
\hline $\begin{array}{c}\text { Pietrasz et al. } \\
{[14]}\end{array}$ & 203 & Yes & Yes & No & Yes & $* * * *$ & * & $* * *$ & 8 \\
\hline $\begin{array}{l}\text { Grose et al., } \\
2017 \text { [24] }\end{array}$ & 85 & Yes & Yes & Yes & No & $* * * *$ & * & $* * *$ & 8 \\
\hline $\begin{array}{l}\text { Fiore et al., } \\
2017 \text { [25] }\end{array}$ & 41 & Yes & Yes & Yes & No & $* * * *$ & * & $* * *$ & 8 \\
\hline $\begin{array}{l}\text { Abbott et al., } \\
2013 \text { [26] }\end{array}$ & 164 & Yes & Yes & No & No & $* * * *$ & * & $* * *$ & 8 \\
\hline $\begin{array}{l}\text { Denost et al., } \\
2012 \text { [27] }\end{array}$ & 111 & Yes & Yes & No & Yes & $* * * *$ & * & $* * *$ & 8 \\
\hline $\begin{array}{l}\text { Habermehl } \\
\text { et al., } 2012 \text { [28] }\end{array}$ & 215 & Yes & Yes & Yes & No & $* * *$ & - & $* * *$ & 6 \\
\hline
\end{tabular}

Newcastle-Ottawa Quality Assessment Scale $\left(^{*}:\right.$ the study met the criteria for a domain of the Newcastle-Ottawa Scale, each * represents if individual criterion within the subsection was fulfilled; -: the criteria were not met). Newcastle-Ottava Scale for Case-Control studies (Selection: 1. Adequacy of case definition, 2. Representativeness of the cases, 3. Selection of controls, 4. Definition of Controls; Comparability: 1. Comparability of cases and controls on the basis of the design; Exposure: 1. Ascertainment of exposure, 2. Same method of ascertainment for cases and con-trols, 3. Non-Response rate) and Cohort studies (Selection: 1. Representativeness of the exposed cohort, 2. Selection of the non-exposed cohort, 3. Ascertainment of exposure, 4. Demonstration that outcome of interest was not present at start of study; Compa-rability: 1. Comparability of cohorts on the basis of the design or analysis; Outcome: 1. Assessment of outcome, 2. Was follow-up long enough for outcomes to occur, 3. Adequacy of follow up of cohorts). 
Patient characteristics are shown in Table 3. A total of 1080 patients with PDAC who underwent IC + CRT were analyzed. In two articles, patients had a diagnosis of resectable I PDAC $[18,26]$. In other articles, patients were classified as BR (N 372, 34\%) or LA (N 477, 44\%). The resectability status and stage were determined according to NCCN guidelines in all selected articles [29]. Gemcitabine alone or combined was the main administered regimen for IC (N 620, 57\%). FOLFIRINOX was the second-most diffused regimen (N 490, 45\%).

\subsection{Response and Tolerance to TNT}

The percentage of patients who completed IC varied from 37\% to $100 \%$. Grade 3 or greater of toxicity during IC was observed in $14-51 \%$ of patients. Disease progression during IC ranged from 3\% to 25\%. Based on available data in $27(10 \%)$ LA and 17 (13\%) BR patients, disease progression during IC was observed. A total of 898 (91\%) received CRT after IC. Capecitabine or Gemcitabine were the most commons regimens combined with radiotherapy. In six studies, radiotherapy was administered with a radiation dose of $50.4 \mathrm{~Gy}$ in 28 fractions combined with Capecitabine or Gemcitabine. Disease progression during CRT was observed from $6 \%$ to $22 \%$ of subjects. A total of $607(62 \%)$ patients underwent curative surgery after IC + CRT. Based on the available data, respectively, 77 (61\%) BR patients and $124(43 \%)$ LA patients underwent surgery after completion of IC + CRT. A total of $107(10 \%)$ patients underwent only surgical exploration after IC + CRT.

\subsection{Pathological, Surgical and Survival Outcomes}

As shown in Table 4, pathological complete response was observed in 36 (5\%) patients. The percentage of regional lymph node metastases varied from $20 \%$ to $56 \%$. R0 resection rates varied from 39.2 to $100 \%$. Major complications after surgery, classified as Clavien Dindo $\geq 3 \mathrm{~b}$, were observed in $12.5-56 \%$ of patients. Median DFS varied from 14.8 to 48.6 months. Median OS varied from 10.8 to 51.5 months.

In Table 5, the main pathological and survival outcomes in patients undergoing curative surgery after completion of TNT were reported, according to stratification by the initial stage. According to the available data, regional lymph node metastases were found in $56 \%$ of R-, $34 \%$ of BR-, and $36 \%$ of LA patients. Resection R0 was found in $90 \%$ of R-, $68 \%$ of BR-, and $66 \%$ of LA patients. Survival outcomes were not available for R patients.

Figure 2 summarized values of 1-year, 2-year, and 3-year OS. Articles with patients with diagnosis of LA PDAC had 1-year OS varying from $60 \%$ to $72 \%$, 2-year OS from $29.2 \%$ to $48 \%$, and 3-year OS from $12.5 \%$ to $15 \%$ [21,28]. Articles with patients with a diagnosis of BR PDAC had a 1-year OS varying from $68.6 \%$ to $71 \%$, and 2 -year OS from $28 \%$ to $35.3 \%[20,22]$.

Articles with FOLFORINOX as the main regimen had a 1-year OS varying from $84 \%$ to $97 \%$, 2-year OS from $70 \%$ to $84 \%$, and 3-year OS from $46 \%$ to $66 \%$ [14,21,22]. Articles with Gemcitabine as the main regimen used had a 1-year OS varying from $60 \%$ to $87 \%$, 2-year OS from $29 \%$ to $68.75 \%$, and 3-year OS from $12.5 \%$ to $51 \%[20,27,28]$.

Figure 3 summarized values of 1-, 2-, and 3-year DFS. The 1-, 2-, and 3-year DFS varied from $50 \%$ to $90 \%, 18 \%$ to $72 \%$, and $5 \%$ to $72 \%$, respectively. Articles with patients with a diagnosis of LA PDAC had 1-year DFS varying from 50\% to $90 \%$, 2-year DFS from $18 \%$ to $45.7 \%$, and 3 -year DFS from $5 \%$ to $37 \%[21,27,28]$. 
Table 3. Characteristic of patients who underwent IC, CRT, and surgery.

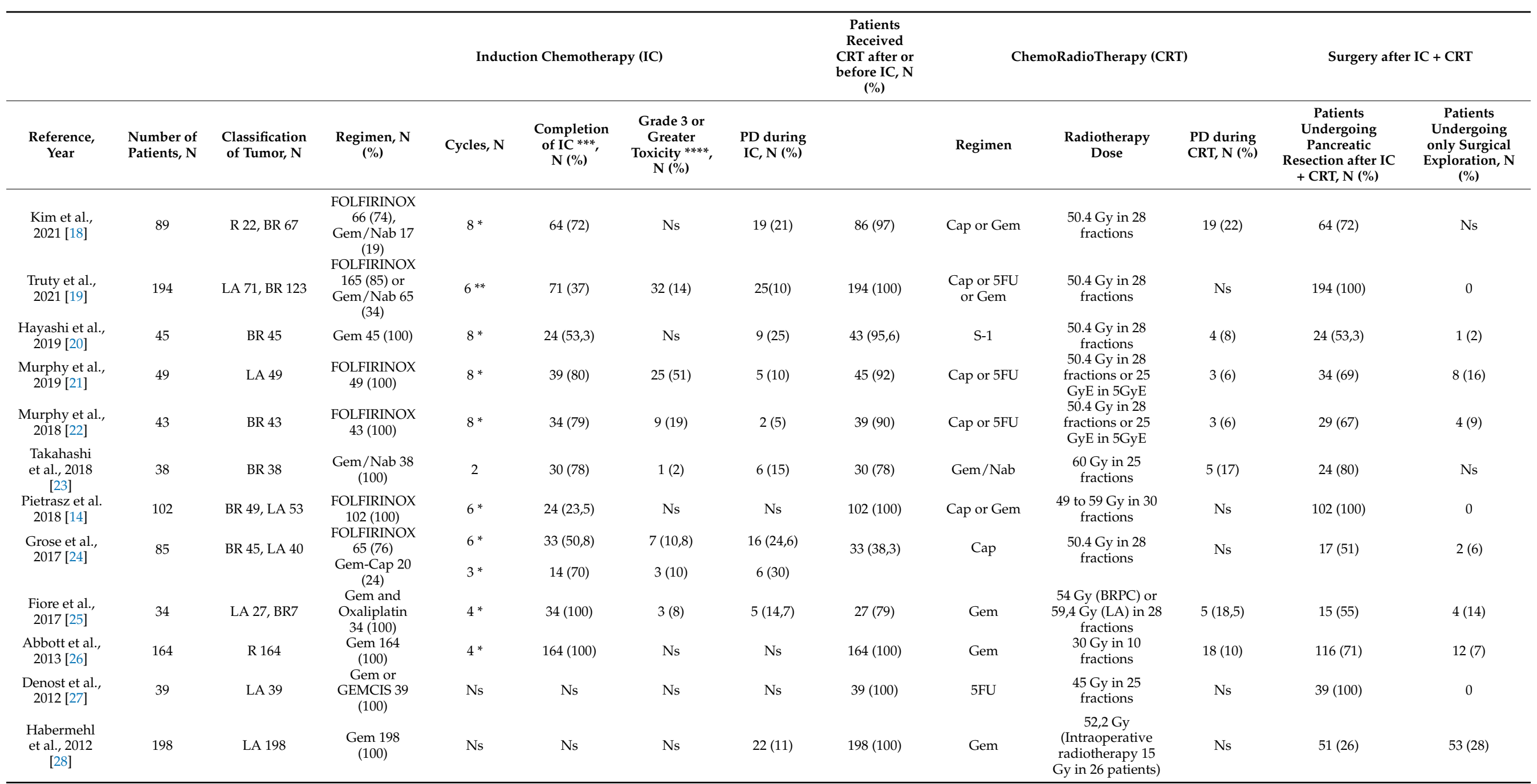

${ }^{*}$ Expected cycles, ${ }^{* *}$ median number of cycles performed, ${ }^{* * *}$ patients who completed IC or made $>8$ cycles, ${ }^{* * * *}$ Criteria for Adverse Events, version 3.0 . IC: induction chemotherapy PD: disease progression; CRT: chemoradiotherapy; LA: locally advanced; BR: borderline resectable; R: resectable; Gem-Nab: Gemcitabine-Nab-paclitaxel, Gem Gemcitabine, Cap Capecitabine; 5-FU: 5 Fluorouracil; FOLFIRINOX: oxaliplatin, irinotecan, fluorouracil, and leucovorin; Ns: not specified. 
Table 4. Pathological characteristics and short-term outcomes of patients who underwent surgery after IC + CRT.

\begin{tabular}{|c|c|c|c|c|c|c|c|c|c|}
\hline \multirow[b]{2}{*}{ Reference } & \multirow[b]{2}{*}{$\begin{array}{c}\text { Patients } \\
\text { Undergone } \\
\text { Surgery after IC } \\
+ \text { CRT, N (\%) }\end{array}$} & \multirow[b]{2}{*}{$\begin{array}{c}\text { Type of } \\
\text { Surgery, N (\%) }\end{array}$} & \multicolumn{3}{|c|}{ Pathological Outcomes } & \multicolumn{2}{|c|}{ Surgical Outcomes } & \multicolumn{2}{|c|}{ Long-Term Outcomes } \\
\hline & & & $\begin{array}{c}\text { Pathological } \\
\text { Complete } \\
\text { Response, } \\
\text { N (\%) }\end{array}$ & $\begin{array}{c}\text { Regional } \\
\text { Lymph Node } \\
\text { Metastases, } \\
\text { N (\%) }\end{array}$ & $\begin{array}{l}\text { Resection } \\
\text { R0, N (\%) }\end{array}$ & $\begin{array}{c}\text { Major } \\
\text { Complications } \\
\text { after Surgery, } \\
\text { N (\%) }\end{array}$ & $\begin{array}{l}90 \text { Day } \\
\text { Mortality, } \\
\text { N (\%) }\end{array}$ & $\begin{array}{c}\text { DFS, } \\
\text { Median } \\
\text { (Months) }\end{array}$ & $\begin{array}{c}\text { OS, } \\
\text { Median } \\
\text { (Months) }\end{array}$ \\
\hline $\begin{array}{l}\text { Kim et al., } \\
2021 \text { [18] }\end{array}$ & $64(72)$ & $\begin{array}{c}\text { PDC } 53(83) \\
\text { DP } 6(9) \\
\text { TP } 5(8)\end{array}$ & $5(8)$ & $25(34)$ & $57(89)$ & $36(56)$ & Ns & Ns & Ns \\
\hline $\begin{array}{l}\text { Truty et al., } \\
2021 \text { [19] }\end{array}$ & $194(100)$ & $\begin{array}{l}\text { PDC } 122(63) \\
\text { TP } 25(13)\end{array}$ & 0 & $39(20)$ & $183(94)$ & $69(36)$ & $13(6,7)$ & 23,5 & 51,1 \\
\hline $\begin{array}{l}\text { Hayashi et al., } \\
2019 \text { [20] }\end{array}$ & $24(53,3)$ & $\begin{array}{c}\text { PDC } 19 \\
\text { DP } 4 \\
\text { TP } 1\end{array}$ & 0 & $6(25)$ & $23(95,8)$ & $6(25)$ & Ns & 14,8 & 27,9 \\
\hline $\begin{array}{c}\text { Murphy et al., } \\
2019[21]\end{array}$ & $34(69)$ & Ns & $3(9)$ & $9(26)$ & $30(88)$ & Ns & Ns & 21,3 & 33 \\
\hline $\begin{array}{l}\text { Murphy et al., } \\
2018 \text { [22] }\end{array}$ & $29(67)$ & Ns & 0 & $20(38)$ & $29(100)$ & Ns & Ns & 48,6 & Ns \\
\hline $\begin{array}{l}\text { Takahashi } \\
\text { et al., } 2018 \text { [23] }\end{array}$ & $24(80)$ & $\begin{array}{l}\text { PDC } 12 \\
\text { DP } 12\end{array}$ & $3(12)$ & Ns & $23(96)$ & $3(12,5)$ & 0 & Ns & Ns \\
\hline $\begin{array}{l}\text { Pietrasz et al. } \\
2018 \text { [14] }\end{array}$ & $102(100)$ & Ns & $22(10,8)$ & $24(23,5)$ & $169(83,3)$ & Ns & Ns & 17.7 & 47.9 \\
\hline $\begin{array}{l}\text { Grose et al., } \\
2017 \text { [24] }\end{array}$ & $17(51)$ & Ns & $3(17)$ & $6(35)$ & $12(70,6)$ & Ns & Ns & Ns & Ns \\
\hline $\begin{array}{c}\text { Fiore et al., } \\
2017 \text { [25] }\end{array}$ & $15(55)$ & Ns & 0 & Ns & $15(100)$ & Ns & 0 & 35,2 & 37,6 \\
\hline $\begin{array}{l}\text { Abbott et al., } \\
2013 \text { [26] }\end{array}$ & $116(71)$ & Ns & Ns & $65(56)$ & $104(90)$ & $27(23)$ & $1(1)$ & Ns & Ns \\
\hline $\begin{array}{c}\text { Denost et al., } \\
2012 \text { [27] }\end{array}$ & $39(100)$ & PDC 39 (100) & Ns & $16(41)$ & $33(84,6)$ & $12(30)$ & Ns & Ns & Ns \\
\hline $\begin{array}{l}\text { Habermehl } \\
\text { et al., } 2012 \text { [28] }\end{array}$ & $51(26)$ & Ns & Ns & Ns & $20(39,2)$ & Ns & Ns & 10,8 & 10,8 \\
\hline
\end{tabular}

PD: pancreaticoduodenectomy; DP: distal pancreatectomy; TP: total pancreatectomy; Ns: not specified; DFS: disease-free survival; OS: overall survival.

Table 5. Pathological characteristics and survival outcomes subdivided for diagnostic classes of patients who underwent surgery after TNT.

\begin{tabular}{cccccccc}
\hline $\begin{array}{c}\text { Classification } \\
\text { of Patients }\end{array}$ & $\begin{array}{c}\text { Patients } \\
\text { Undergone } \\
\text { Surgery after TNT }\end{array}$ & $\begin{array}{c}\text { Regional Lymph } \\
\text { Node Metastases, } \\
\text { N (\%) }\end{array}$ & $\begin{array}{c}\text { Resection R0, } \\
\text { N (\%) }\end{array}$ & 1-Year OS & 2-Years OS & 1-Year DFS & 2-Years DFS \\
\hline $\begin{array}{c}\text { Resectable } \\
\begin{array}{c}\text { Borderline } \\
\text { resectable } \\
\text { Locally } \\
\text { advanced }\end{array}\end{array}$ & 116 & $65(56 \%)$ & $104(90 \%)$ & $\mathrm{ns}$ & $\mathrm{ns}$ & $\mathrm{ns}$ & $\mathrm{ns}$ \\
\hline
\end{tabular}

ns: not specified.

\subsection{Meta-Analysis: Pathological and Survival outcomes}

Three studies described comparable patient groups in terms of pathological outcomes and two studies in terms of survival outcomes (Table 6); thus, a metanalysis was attempted [14,18,20,24].

All three studies investigating patients with PDAC undergoing TNT followed by surgery in comparison with patients undergoing surgery after NAT assessed an intervention group versus a control group. A total of 623 patients have been evaluated, of which 183 underwent intention-to-treat surgery after TNT and 440 underwent intention-to-treat surgery after NAT. As shown in Figure 4, three studies reported data on lymph node metastases and radicality, with a significant benefit for TNT groups (OR 1.77, 95\% CI 1.2-2.60, $p=0.004$ and OR 2.03, 95\% CI 1.19-2.60, $p=0.01$, respectively) $[14,18,24]$. Furthermore, two studies reported data of 1-year OS and 2-year OS with a significant benefit in favor of the TNT group (OR 1.88, CI 1.13-3.13, $p=0.02$ and OR 1.64, CI 1.09-2.47, $p=0.02$ ) $[14,18]$. 


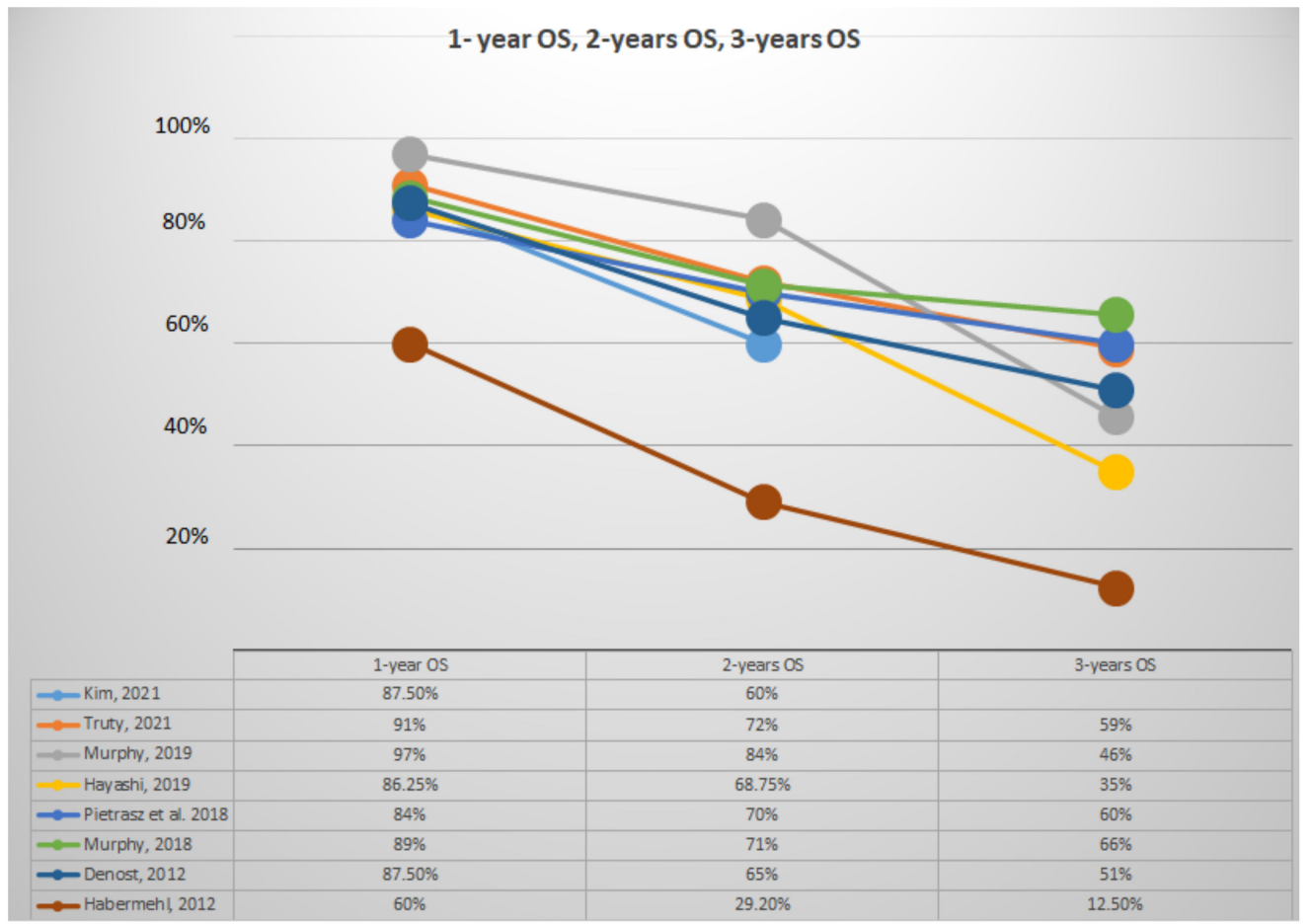

Figure 2. Representative analysis of 1-, 2-, and 3-year OS.

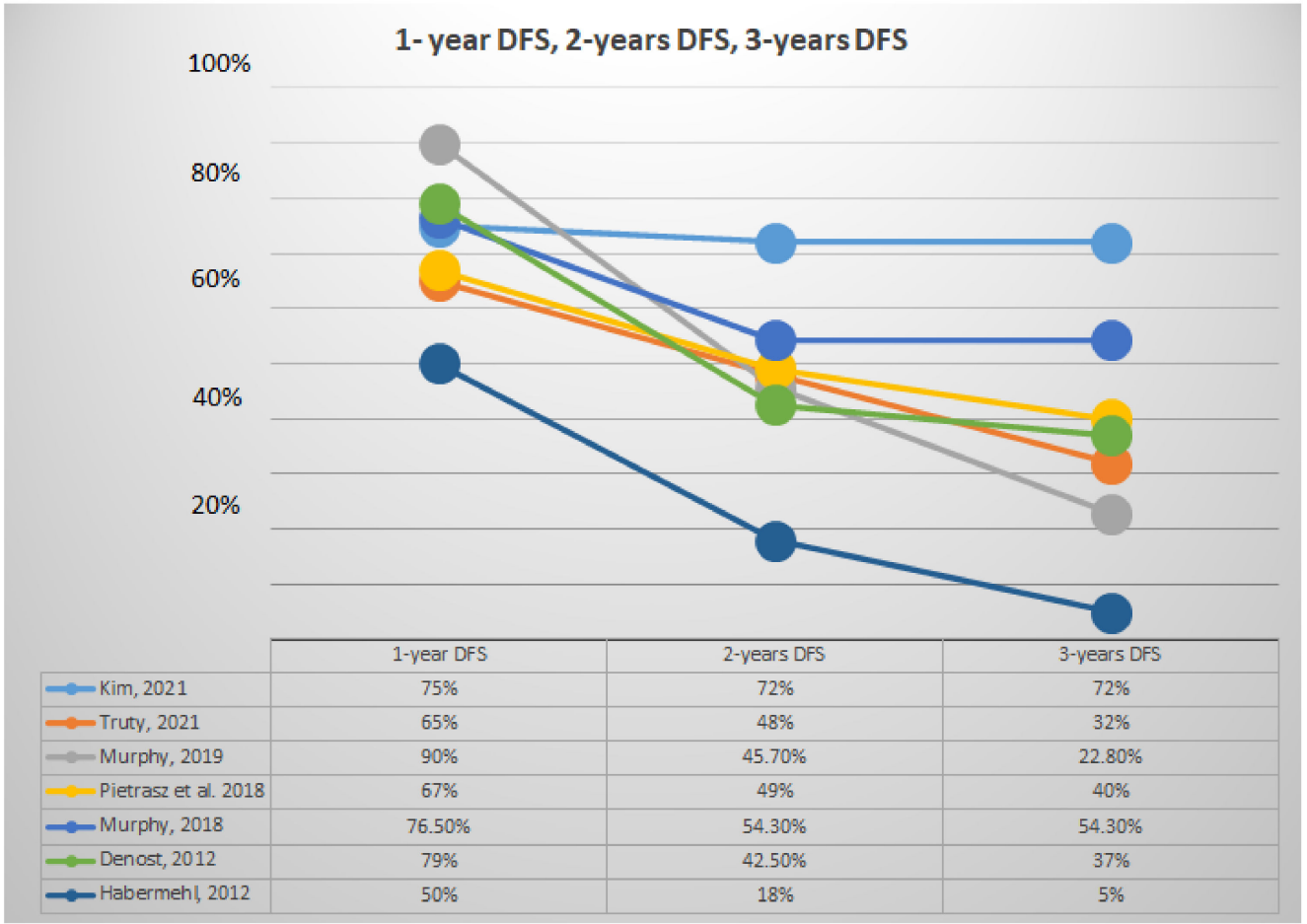

Figure 3. Representative analysis of 1-, 2-, and 3-year DFS. 
Table 6. Comparison between patients with PDAC who underwent Surgery after TNT versus Surgery after NAT.

\begin{tabular}{|c|c|c|c|c|c|c|c|c|c|c|c|c|}
\hline \multirow{3}{*}{ Reference } & \multirow{3}{*}{$\begin{array}{c}\text { Patients } \\
\text { Undergone } \\
\text { Surgery } \\
\text { after IC + } \\
\text { CRT, N (\%) }\end{array}$} & \multirow{3}{*}{$\begin{array}{c}\text { Patients } \\
\text { Undergone } \\
\text { Surgery } \\
\text { after NAT }\end{array}$} & \multicolumn{6}{|c|}{ Pathological Outcomes } & \multirow{2}{*}{\multicolumn{2}{|c|}{$\begin{array}{c}\text { Surgical Outcomes } \\
\begin{array}{c}\text { Major Complications } \\
\text { after } \\
\text { Surgery, N (\%) }\end{array}\end{array}$}} & \multirow{2}{*}{\multicolumn{2}{|c|}{\begin{tabular}{|c|}
$\begin{array}{c}\text { Long-Term } \\
\text { Outcomes }\end{array}$ \\
1-Year, 2-Year, \\
3-Year OS, \\
Percentage
\end{tabular}}} \\
\hline & & & \multicolumn{2}{|c|}{$\begin{array}{c}\text { Pathological } \\
\text { Complete } \\
\text { Response, N (\%) }\end{array}$} & \multicolumn{2}{|c|}{$\begin{array}{c}\text { Regional Lymph } \\
\text { Node Metastases, } \\
\text { N (\%) }\end{array}$} & \multicolumn{2}{|c|}{$\begin{array}{c}\text { Resection R0, } \\
\text { N (\%) }\end{array}$} & & & & \\
\hline & & & TNT & NAT & TNT & NAT & TNT & NAT & TNT & NAT & TNT & NAT \\
\hline $\begin{array}{l}\text { Kim et al., } \\
2021 \text { [18] }\end{array}$ & 64 & 322 & $5(8)$ & $13(4)$ & $25(34)$ & $122(38)$ & $57(89)$ & $275(85)$ & $36(56)$ & $189(59)$ & $\begin{array}{c}87,5 \% \\
60 \% \\
\text { Ns }\end{array}$ & $\begin{array}{l}80 \%, \\
52 \%, \\
37 \%\end{array}$ \\
\hline $\begin{array}{c}\text { Grose } \\
\text { et al.,2017 } \\
{[24]}\end{array}$ & 17 & 17 & $3(17)$ & Ns & $6(35)$ & $11(64)$ & $\begin{array}{c}12 \\
(70,6)\end{array}$ & $7(47,6)$ & Ns & Ns & Ns & Ns \\
\hline $\begin{array}{c}\text { Pietrasz } \\
\text { et al. } 2018 \\
\text { [14] }\end{array}$ & 102 & 101 & $17(16,7)$ & $5(5)$ & $\begin{array}{c}24 \\
(23,5)\end{array}$ & $\begin{array}{c}52 \\
(51,5)\end{array}$ & $\begin{array}{c}91 \\
(89,2)\end{array}$ & $\begin{array}{c}78 \\
(76,3)\end{array}$ & Ns & Ns & $\begin{array}{l}84 \%, \\
70 \%, \\
60 \%\end{array}$ & $\begin{array}{l}80 \%, \\
63 \%, \\
44 \%\end{array}$ \\
\hline
\end{tabular}

Ns: not specified.

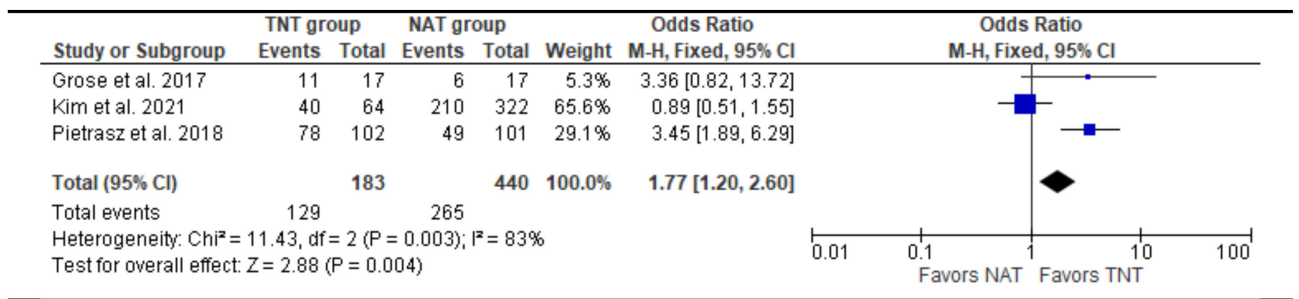

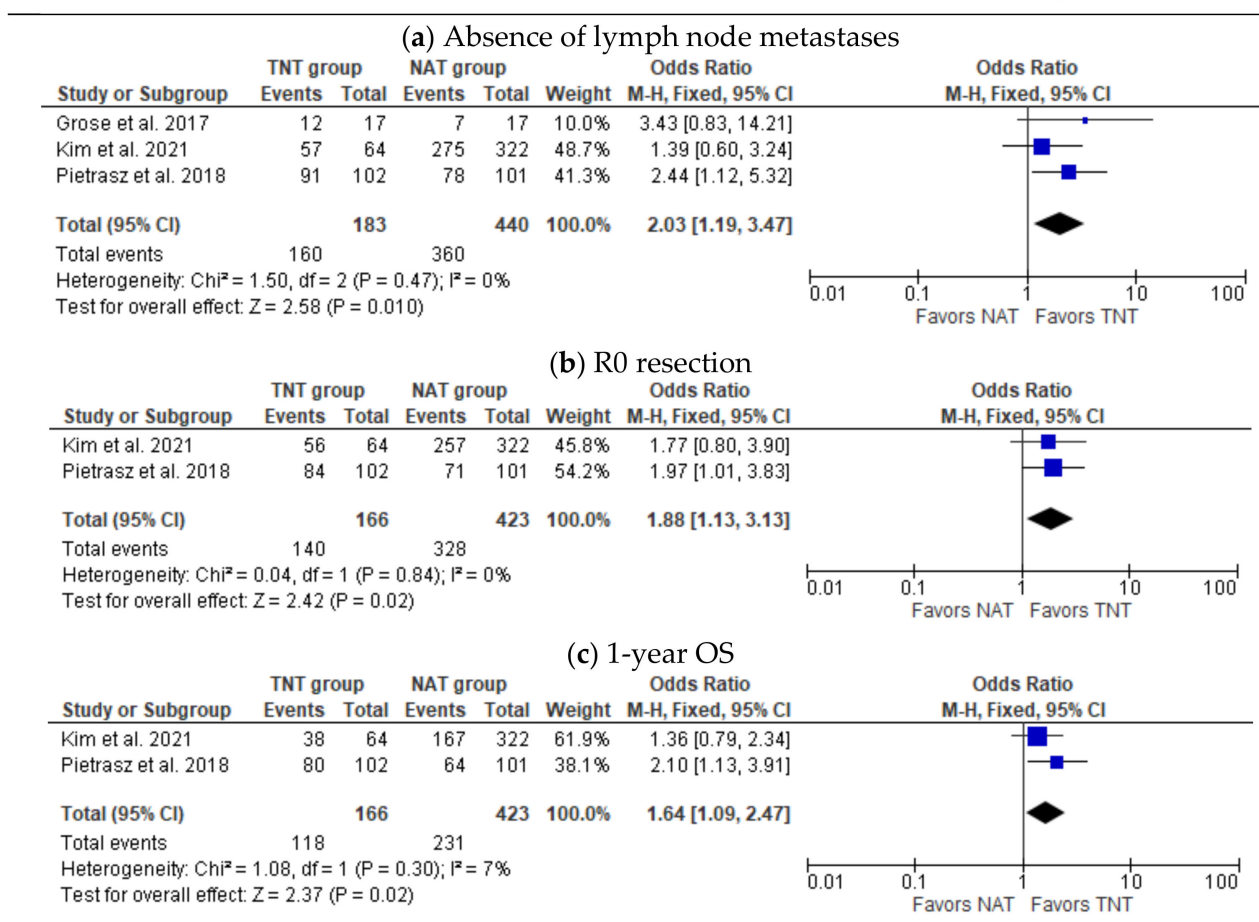

(d) 2-year OS

Figure 4. Meta-analysis of study on pathological and survival outcomes. (a) Forest plot of absence of lymph node metastases (b) Forest plot of R0 resection (c) Forest plot of 1-year OS (d) Forest plot of 2-year OS.

\section{Discussion}

PDAC remains one of the most lethal malignancies, with an overall 5-year survival rate of approximately $5 \%$ [30,31]. Unfortunately, only $15-20 \%$ of PDAC patients are diagnosed early enough to be resectable and about $50 \%$ of them are diagnosed at a metastatic stage $[6,32,33]$. 
The improvement in overall survival with adjuvant systemic chemotherapy with 5-fluorouracil plus folinic acid (ESPAC-1 trial) or gemcitabine plus capecitabine (ESPAC-4 trial) has shown a further step change in survival after resection for PDAC [34,35]. Consequently, surgical resection followed by adjuvant chemotherapy is currently considered the best chance of curative treatment and long-term survival for patients with PDAC. Unfortunately, patients who underwent curative surgery were not always eligible and fit enough for adjuvant chemotherapy [13].

In the last years, NAT in PDAC has received both approval and criticism. On the one hand, its benefits are evident, such as the downstaging of large tumors to allow margin negative resections, better patient selection for resection by revealing biological aggressiveness, and the enablement of further observation of indeterminate extrapancreatic lesions prior to resection; on the other hand, the main debate is about the real prognostic advantage and the risk of losing the opportunity of surgery in some patients [9-12,36]. Recently, TNT has been taking hold in PDAC, based upon excellent results in other types of cancers [37]. IC before CRT may give the theoretical and potential chance to eradicate distant micrometastases at an early stage in the evolution of the disease. Tumor shrinkage after systemic chemotherapy potentially allows improved tumor vascularity that has the consequence of higher intratumoral levels of cytotoxic drugs and higher tumoral sensitivity to CRT [38]. Nevertheless, IC can potentially delay a surgical treatment or select radioresistant clones, allowing distant seeding and reducing compliance to CRT [39].

Our review showed that the main regimens utilized for IC were Gemcitabine-based and FOLFIRINOX. Despite the increasing interest in TNT for PDAC, an optimal chemotherapy protocol and the proper regimen for IC remains to be established. Patients who completed IC varied from $53.3 \%$ to $100 \%$ in the Gemcitabine group and from $50.8 \%$ to $80 \%$ in the FOLFIRINOX group. One of the main criticisms directed to IC was the potential toxicity that could result in missing the surgical intent. This is a controversial issue: as underlined by Ioka et al., a regimen with IC followed by CRT was less toxic than a regimen with only CRT, and patients lost during IC are more likely due to disease progression than toxicity [36]. As shown in Table 3, this concept is well observed in the Gemcitabine regimens where the toxicity varied from $2 \%$ to $10 \%$ and disease progression during IC varied from $11 \%$ to $30 \%$. Differently, the FOLFIRINOX regimens showed more toxicity (10.8\% to $51 \%$ ) but less disease progression ( $5 \%$ to $16 \%$ ). Consequently, the drop-out rate during IC is largely due to disease progression. As suggested by Abbott et al., these patients present aggressive tumor biology, prone to rapid progression in distant sites, reducing the potential survival benefit of surgery [26]. The benefit of selecting in- (and out-) patients who will (or will not) benefit from CRT should be seen as an advantage of IC [40]. Furthermore, the dropout rate during IC still remains lower than the $24-50 \%$ of patients undergoing upfront surgery, who are ineligible to receive adjuvant chemotherapy [41].

The role of CRT in PDAC finds its main rationale in the high local aggressiveness of the disease with a high risk of local recurrence after surgery and high rates of involvement of retroperitoneal margins [11]. Surgical radicality is one of the most important prognostic factors in PDAC $[39,40]$. In resectable PDAC undergone upfront surgery, Ryan et al., found a $40 \%$ to $70 \%$ chance of $\mathrm{R} 1$ resection [32]. Surgical radicality is even more challenging in certain categories of patients with PDAC, such as LA and BR, mostly represented in our review. In the literature, the role of CRT has long been investigated, especially in its adjuvant setting, where its role is controversial $[35,42,43]$.

As shown in Table 3, patients who received CRT after IC varied from $38.3 \%$ to $100 \%$. In prospective studies, this percentage varied from $78 \%$ to $95,6 \%$. Despite expected problems of toxicity or disease progression, the majority of patients enrolled for TNT were eligible for CRT. The variability of CRT regimens was also reported: the majority of authors used the same radiotherapy dose of 50.4 Gy given in 28 fractions, while the most frequent concurrent chemotherapy regimens were Gemcitabine or Capecitabine. As underlined by Mukherjee, Gemcitabine is a more potent radiosensitizer than Capecitabine; however, the 
systemic effect of concomitant chemotherapy during radiotherapy seems to account for the difference [44].

Patients who completed TNT and underwent surgery with curative intent varied from $26 \%$ to $100 \%$. Within this variability of drop-out rate, we found both patients who could not benefit from surgical treatment and patients who underwent surgical treatment without completing TNT. Unfortunately, articles do not quantify the latter category of patients.

The uncertainty of not reaching surgical resection is one of the debated topics in neoadjuvant therapy; our review showed that patients who underwent only exploratory laparotomy varied from $2 \%$ to $28 \%$, with the highest percentages among patients with a diagnosis of LA PDAC $[21,25,28]$. The resectability rates after TNT, shown in Tables 3 and 5 , tended to be similar or higher than those reported in the literature after neoadjuvant therapy, also considering authors such as Palmer et al., who showed a resectability rate of $54 \%$ in patients with resectable (R) PDAC after NAT; and Versteijne et al., who reported a resection rate for patients with $\mathrm{R}$ and $\mathrm{BR}$ pancreatic cancer of $67 \%$ and $65 \%$, respectively [45].

The wide heterogeneity and range of data reported in selected articles are certainly due to different nature of studies; in particular, retrospective articles showed better surgical and oncological outcomes, with resection rates up to $100 \%$; we can speculate that better results could depend on implicit selection bias with the recruitment of patients who are fitter for TNT and surgery. On the contrary, prospective studies showed higher percentages of drop-out and worse surgical and oncological outcomes. Furthermore, the median OS varied widely across the articles, as shown in Table 4, ranging from 10,8 to 51,1 months: this can be explained firstly by the different group of patients at diagnosis, as confirmed by data reported in Table 5 with patients stratified by the initial stage of disease. Nevertheless, initial chemotherapy regimens seem to play an equally determinant role in surgical and oncological outcomes. In Figures 2 and 3, we showed survival trends in the first 3 years after surgery: both OS and DFS seemed to be more influenced by the type of IC regimen administered than by the initial stage and completion of CRT. In particular, articles with FOLFIRINOX as the predominant chemotherapy regimen seemed to have better survival outcomes [14,18,19,21,22]. This finding is consistent with the observation that PDAC should be considered a systemic disease, which could benefit from an aggressive systemic chemotherapy. Nonetheless, as shown in Table 6 and Figure 4, articles reporting comparison among patients $(10.5 \% \mathrm{R}, 65 \% \mathrm{BR}, 24.5 \% \mathrm{LA})$ treated with TNT and NAT showed better pathological and oncological outcomes in favor of the TNT group, even though the results could be affected by IC regimen.

\section{Conclusions}

To our knowledge, this is the first systematic review investigating the role of TNT and surgery with curative intent in PDAC, with a comparison to NAT without CRT. Several limitations need to be considered when interpreting our data: the retrospective nature of some articles, the wide heterogeneity of IC and CRT regimens, and different groups of patients starting TNT, which make it difficult to obtain homogeneous and easily comparable results.

However, despite its limitations, this review suggests that TNT can be considered a good therapeutic pathway for patients, especially BR- and LA PDAC ones, who may benefit from surgical treatment with curative intent, with good survival and acceptable morbidity. Moreover, current evidence demonstrates the potential superiority of TNT compared to NAT without CRT in oncological and pathological outcomes, in particular in patients with doubtful resectability at the end of neoadjuvant treatment.

Prospective randomized trials are certainly needed to verify whether TNT can be considered a standard of care in patients with PDAC, to determine the best IC and CRT regimen, and to identify which patients may benefit the most from this therapeutic approach.

Author Contributions: Conceptualization, O.D.S., C.S., and M.G.; methodology, O.D.S., M.S., and M.G.; software, O.D.S.; validation, M.G. and P.P.; formal analysis, O.D.S. and M.G.; investigation, O.D.S., C.S., F.B., S.L., and M.G.; resources, O.D.S., C.S., A.F., F.B., and M.G.; data curation, O.D.S., C.S., S.L., and M.G.; writing-original draft preparation, O.D.S. and M.G.; writing-review and 
editing, O.D.S., C.S., A.F., S.L., and M.G.; visualization, O.D.S. and M.G; supervision, M.G. and P.P. All authors have read and agreed to the published version of the manuscript.

Funding: This research received no external funding.

Institutional Review Board Statement: Not applicable.

Informed Consent Statement: Not applicable.

Data Availability Statement: Data analyzed is contained within the article.

Acknowledgments: Preliminary data reported in this review have been accepted as abstract for presentation at the 15th IHPBA World Congress, 30 March-2 April 2022, New York, NY, USA.

Conflicts of Interest: The authors declare no conflict of interest.

\section{References}

1. Howlader, N.; Noone, A.M.; Krapcho, M.; Miller, D.; Bishop, K.; Altekruse, S.F.; Kosary, C.L.; Yu, M.; Ruhl, J.; Tatalovich, Z.; et al. SEER Cancer Statistics Review, 1975-2013; National Cancer Institute: Bethesda, MD, USA, 2016.

2. Hartwig, W.; Werner, J.; Jäger, D.; Debus, J.; Büchler, M.W. Improvement of Surgical Results for Pancreatic Cancer. Lancet Oncol. 2013, 14, e476-e485. [CrossRef]

3. Kleeff, J.; Korc, M.; Apte, M.; La Vecchia, C.; Johnson, C.D.; Biankin, A.V.; Neale, R.E.; Tempero, M.; Tuveson, D.A.; Hruban, R.H.; et al. Pancreatic Cancer. Nat. Rev. Dis. Primers 2016, 2, 16022. [CrossRef] [PubMed]

4. Conlon, K.C.; Klimstra, D.S.; Brennan, M.F. Long-Term Survival after Curative Resection for Pancreatic Ductal Adenocarcinoma. Clinicopathologic Analysis of 5-Year Survivors. Ann. Surg. 1996, 223, 273-279. [CrossRef] [PubMed]

5. Chua, Y.J.; Cunningham, D. Adjuvant Treatment for Resectable Pancreatic Cancer. J. Clin. Oncol. 2005, 23, 4532-4537. [CrossRef] [PubMed]

6. Gillen, S.; Schuster, T.; Meyer zum Büschenfelde, C.; Friess, H.; Kleeff, J. Preoperative/Neoadjuvant Therapy in Pancreatic Cancer: A Systematic Review and Meta-Analysis of Response and Resection Percentages. PLoS Med. 2010, 7, e1000267. [CrossRef] [PubMed]

7. Gemenetzis, G.; Groot, V.P.; Blair, A.B.; Laheru, D.A.; Zheng, L.; Narang, A.K.; Fishman, E.K.; Hruban, R.H.; Yu, J.; Burkhart, R.A.; et al. Survival in Locally Advanced Pancreatic Cancer After Neoadjuvant Therapy and Surgical Resection. Ann. Surg. 2019, 270, 340-347. [CrossRef]

8. Hackert, T.; Sachsenmaier, M.; Hinz, U.; Schneider, L.; Michalski, C.W.; Springfeld, C.; Strobel, O.; Jäger, D.; Ulrich, A.; Büchler, M.W. Locally Advanced Pancreatic Cancer: Neoadjuvant Therapy with Folfirinox Results in Resectability in $60 \%$ of the Patients. Ann. Surg. 2016, 264, 457-463. [CrossRef]

9. Ferrone, C.R.; Marchegiani, G.; Hong, T.S.; Ryan, D.P.; Deshpande, V.; McDonnell, E.I.; Sabbatino, F.; Santos, D.D.; Allen, J.N.; Blaszkowsky, L.S.; et al. Radiological and Surgical Implications of Neoadjuvant Treatment with FOLFIRINOX for Locally Advanced and Borderline Resectable Pancreatic Cancer. Ann. Surg. 2015, 261, 12-17. [CrossRef]

10. Miyasaka, Y.; Ohtsuka, T.; Kimura, R.; Matsuda, R.; Mori, Y.; Nakata, K.; Kakihara, D.; Fujimori, N.; Ohno, T.; Oda, Y.; et al. Neoadjuvant Chemotherapy with Gemcitabine Plus Nab-Paclitaxel for Borderline Resectable Pancreatic Cancer Potentially Improves Survival and Facilitates Surgery. Ann. Surg. Oncol. 2019, 26, 1528-1534. [CrossRef]

11. Versteijne, E.; Suker, M.; Groothuis, K.; Akkermans-Vogelaar, J.M.; Besselink, M.G.; Bonsing, B.A.; Buijsen, J.; Busch, O.R.; Creemers, G.-J.M.; van Dam, R.M.; et al. Preoperative Chemoradiotherapy Versus Immediate Surgery for Resectable and Borderline Resectable Pancreatic Cancer: Results of the Dutch Randomized Phase III PREOPANC Trial. J. Clin. Oncol. 2020, 38, 1763-1773. [CrossRef]

12. Tang, K.; Lu, W.; Qin, W.; Wu, Y. Neoadjuvant Therapy for Patients with Borderline Resectable Pancreatic Cancer: A Systematic Review and Meta-Analysis of Response and Resection Percentages. Pancreatology 2016, 16, 28-37. [CrossRef] [PubMed]

13. Turpin, A.; El Amrani, M.; Bachet, J.-B.; Pietrasz, D.; Schwarz, L.; Hammel, P. Adjuvant Pancreatic Cancer Management: Towards New Perspectives in 2021. Cancers 2020, 12, E3866. [CrossRef] [PubMed]

14. Pietrasz, D.; Turrini, O.; Vendrely, V.; Simon, J.-M.; Hentic, O.; Coriat, R.; Portales, F.; Le Roy, B.; Taieb, J.; Regenet, N.; et al. How Does Chemoradiotherapy Following Induction FOLFIRINOX Improve the Results in Resected Borderline or Locally Advanced Pancreatic Adenocarcinoma? An AGEO-FRENCH Multicentric Cohort. Ann. Surg. Oncol. 2019, 26, 109-117. [CrossRef] [PubMed]

15. Hammel, P.; Huguet, F.; van Laethem, J.-L.; Goldstein, D.; Glimelius, B.; Artru, P.; Borbath, I.; Bouché, O.; Shannon, J.; André, T.; et al. Effect of Chemoradiotherapy vs Chemotherapy on Survival in Patients with Locally Advanced Pancreatic Cancer Controlled After 4 Months of Gemcitabine With or Without Erlotinib: The LAP07 Randomized Clinical Trial. JAMA 2016, 315, 1844-1853. [CrossRef] [PubMed]

16. Moher, D.; Liberati, A.; Tetzlaff, J.; Altman, D.G.; The PRISMA Group. Preferred Reporting Items for Systematic Reviews and Meta-Analyses: The PRISMA Statement. PLoS Med. 2009, 6, e1000097. [CrossRef]

17. Higgins, J.P.T.; Thompson, S.G.; Deeks, J.J.; Altman, D.G. Measuring Inconsistency in Meta-Analyses. BMJ 2003, 327, 557-560. [CrossRef] 
18. Kim, R.Y.; Christians, K.K.; Aldakkak, M.; Clarke, C.N.; George, B.; Kamgar, M.; Khan, A.H.; Kulkarni, N.; Hall, W.A.; Erickson, B.A.; et al. Total Neoadjuvant Therapy for Operable Pancreatic Cancer. Ann. Surg. Oncol. 2021, 28, 2246-2256. [CrossRef]

19. Truty, M.J.; Kendrick, M.L.; Nagorney, D.M.; Smoot, R.L.; Cleary, S.P.; Graham, R.P.; Goenka, A.H.; Hallemeier, C.L.; Haddock, M.G.; Harmsen, W.S.; et al. Factors Predicting Response, Perioperative Outcomes, and Survival Following Total Neoadjuvant Therapy for Borderline/Locally Advanced Pancreatic Cancer. Ann. Surg. 2021, 273, 341-349. [CrossRef]

20. Hayashi, T.; Nakamura, T.; Kimura, Y.; Yoshida, M.; Someya, M.; Kawakami, H.; Sakuhara, Y.; Katoh, N.; Takahashi, K.; Ambo, Y.; et al. Phase 2 Study of Neoadjuvant Treatment of Sequential S-1-Based Concurrent Chemoradiation Therapy Followed by Systemic Chemotherapy with Gemcitabine for Borderline Resectable Pancreatic Adenocarcinoma (HOPS-BR 01). Int. J. Radiat. Oncol. Biol. Phys. 2019, 105, 606-617. [CrossRef]

21. Murphy, J.E.; Wo, J.Y.; Ryan, D.P.; Clark, J.W.; Jiang, W.; Yeap, B.Y.; Drapek, L.C.; Ly, L.; Baglini, C.V.; Blaszkowsky, L.S.; et al. Total Neoadjuvant Therapy with FOLFIRINOX in Combination With Losartan Followed by Chemoradiotherapy for Locally Advanced Pancreatic Cancer: A Phase 2 Clinical Trial. JAMA Oncol. 2019, 5, 1020-1027. [CrossRef]

22. Murphy, J.E.; Wo, J.Y.; Ryan, D.P.; Jiang, W.; Yeap, B.Y.; Drapek, L.C.; Blaszkowsky, L.S.; Kwak, E.L.; Allen, J.N.; Clark, J.W.; et al. Total Neoadjuvant Therapy with FOLFIRINOX Followed by Individualized Chemoradiotherapy for Borderline Resectable Pancreatic Adenocarcinoma: A Phase 2 Clinical Trial. JAMA Oncol. 2018, 4, 963-969. [CrossRef] [PubMed]

23. Takahashi, H.; Akita, H.; Ioka, T.; Wada, H.; Tomokoni, A.; Asukai, K.; Ohue, M.; Yano, M.; Ishikawa, O. Phase I Trial Evaluating the Safety of Preoperative Gemcitabine/Nab-Paclitaxel with Concurrent Radiation Therapy for Borderline Resectable Pancreatic Cancer. Pancreas 2018, 47, 1135-1141. [CrossRef] [PubMed]

24. Grose, D.; McIntosh, D.; Jamieson, N.; Carter, R.; Dickson, E.; Chang, D.; Marashi, H.; Wilson, C.; Alfayez, M.; Kerr, A.; et al. The Role of Induction Chemotherapy + Chemoradiotherapy in Localised Pancreatic Cancer: Initial Experience in Scotland. J. Gastrointest. Oncol. 2017, 8, 683-695. [CrossRef] [PubMed]

25. Fiore, M.; Ramella, S.; Valeri, S.; Caputo, D.; Floreno, B.; Trecca, P.; Trodella, L.E.; Trodella, L.; D’Angelillo, R.M.; Coppola, R. Phase II Study of Induction Chemotherapy Followed by Chemoradiotherapy in Patients with Borderline Resectable and Unresectable Locally Advanced Pancreatic Cancer. Sci. Rep. 2017, 7, 45845. [CrossRef]

26. Abbott, D.E.; Tzeng, C.-W.D.; Merkow, R.P.; Cantor, S.B.; Chang, G.J.; Katz, M.H.; Bentrem, D.J.; Bilimoria, K.Y.; Crane, C.H.; Varadhachary, G.R.; et al. The Cost-Effectiveness of Neoadjuvant Chemoradiation Is Superior to a Surgery-First Approach in the Treatment of Pancreatic Head Adenocarcinoma. Ann. Surg. Oncol. 2013, 20 (Suppl. 3), S500-S508. [CrossRef]

27. Denost, Q.; Laurent, C.; Adam, J.-P.; Capdepont, M.; Vendrely, V.; Collet, D.; Cunha, A.S. Pancreaticoduodenectomy Following Chemoradiotherapy for Locally Advanced Adenocarcinoma of the Pancreatic Head. HPB Oxf. 2013, 15, 716-723. [CrossRef]

28. Habermehl, D.; Kessel, K.; Welzel, T.; Hof, H.; Abdollahi, A.; Bergmann, F.; Rieken, S.; Weitz, J.; Werner, J.; Schirmacher, P.; et al. Neoadjuvant Chemoradiation with Gemcitabine for Locally Advanced Pancreatic Cancer. Radiat. Oncol. 2012, 7, 28. [CrossRef]

29. Tempero, M.A.; Malafa, M.P.; Al-Hawary, M.; Behrman, S.W.; Benson, A.B.; Cardin, D.B.; Chiorean, E.G.; Chung, V.; Czito, B.; Del Chiaro, M.; et al. Pancreatic Adenocarcinoma, Version 2.2021, NCCN Clinical Practice Guidelines in Oncology. J. Natl. Compr. Canc. Netw. 2021, 19, 439-457. [CrossRef]

30. Welsch, T.; Kleeff, J.; Friess, H. Molecular Pathogenesis of Pancreatic Cancer: Advances and Challenges. Curr. Mol. Med. 2007, 7, 504-521. [CrossRef] [PubMed]

31. Siegel, R.L.; Miller, K.D.; Fuchs, H.E.; Jemal, A. Cancer Statistics, 2021. CA Cancer J. Clin. 2021, 71, 7-33. [CrossRef]

32. Ryan, D.P.; Hong, T.S.; Bardeesy, N. Pancreatic Adenocarcinoma. New Engl. J. Med. 2014, 371, 1039-1049. [CrossRef]

33. He, J.; Ahuja, N.; Makary, M.A.; Cameron, J.L.; Eckhauser, F.E.; Choti, M.A.; Hruban, R.H.; Pawlik, T.M.; Wolfgang, C.L. 2564 Resected Periampullary Adenocarcinomas at a Single Institution: Trends over Three Decades. HPB Oxf. 2014, 16, 83-90. [CrossRef] [PubMed]

34. Neoptolemos, J.P.; Palmer, D.H.; Ghaneh, P.; Psarelli, E.E.; Valle, J.W.; Halloran, C.M.; Faluyi, O.; O’Reilly, D.A.; Cunningham, D.; Wadsley, J.; et al. Comparison of Adjuvant Gemcitabine and Capecitabine with Gemcitabine Monotherapy in Patients with Resected Pancreatic Cancer (ESPAC-4): A Multicentre, Open-Label, Randomised, Phase 3 Trial. Lancet 2017, 389, 1011-1024. [CrossRef]

35. Neoptolemos, J.P.; Dunn, J.A.; Stocken, D.D.; Almond, J.; Link, K.; Beger, H.; Bassi, C.; Falconi, M.; Pederzoli, P.; Dervenis, C.; et al. Adjuvant Chemoradiotherapy and Chemotherapy in Resectable Pancreatic Cancer: A Randomised Controlled Trial. Lancet 2001, 358, 1576-1585. [CrossRef]

36. Ioka, T.; Furuse, J.; Fukutomi, A.; Mizusawa, J.; Nakamura, S.; Hiraoka, N.; Ito, Y.; Katayama, H.; Ueno, M.; Ikeda, M.; et al. Randomized Phase II Study of Chemoradiotherapy with versus without Induction Chemotherapy for Locally Advanced Pancreatic Cancer: Japan Clinical Oncology Group Trial, JCOG1106. Jpn. J. Clin. Oncol. 2021, 51, 235-243. [CrossRef] [PubMed]

37. Petrelli, F.; Trevisan, F.; Cabiddu, M.; Sgroi, G.; Bruschieri, L.; Rausa, E.; Ghidini, M.; Turati, L. Total Neoadjuvant Therapy in Rectal Cancer: A Systematic Review and Meta-Analysis of Treatment Outcomes. Ann. Surg. 2020, 271, 440-448. [CrossRef]

38. Taghian, A.G.; Abi-Raad, R.; Assaad, S.I.; Casty, A.; Ancukiewicz, M.; Yeh, E.; Molokhia, P.; Attia, K.; Sullivan, T.; Kuter, I.; et al. Paclitaxel Decreases the Interstitial Fluid Pressure and Improves Oxygenation in Breast Cancers in Patients Treated with Neoadjuvant Chemotherapy: Clinical Implications. J. Clin. Oncol. 2005, 23, 1951-1961. [CrossRef]

39. Glynne-Jones, R.; Grainger, J.; Harrison, M.; Ostler, P.; Makris, A. Neoadjuvant Chemotherapy Prior to Preoperative Chemoradiation or Radiation in Rectal Cancer: Should We Be More Cautious? Br. J. Cancer 2006, 94, 363-371. [CrossRef] 
40. Krishnan, S.; Rana, V.; Janjan, N.A.; Varadhachary, G.R.; Abbruzzese, J.L.; Das, P.; Delclos, M.E.; Gould, M.S.; Evans, D.B.; Wolff, R.A.; et al. Induction Chemotherapy Selects Patients with Locally Advanced, Unresectable Pancreatic Cancer for Optimal Benefit from Consolidative Chemoradiation Therapy. Cancer 2007, 110, 47-55. [CrossRef]

41. Mayo, S.C.; Austin, D.F.; Sheppard, B.C.; Mori, M.; Shipley, D.K.; Billingsley, K.G. Adjuvant Therapy and Survival after Resection of Pancreatic Adenocarcinoma: A Population-Based Analysis. Cancer 2010, 116, 2932-2940. [CrossRef]

42. Kalser, M.H.; Ellenberg, S.S. Pancreatic Cancer. Adjuvant Combined Radiation and Chemotherapy Following Curative Resection. Arch. Surg. 1985, 120, 899-903. [CrossRef] [PubMed]

43. Smeenk, H.G.; van Eijck, C.H.J.; Hop, W.C.; Erdmann, J.; Tran, K.C.K.; Debois, M.; van Cutsem, E.; van Dekken, H.; Klinkenbijl, J.H.; Jeekel, J. Long-Term Survival and Metastatic Pattern of Pancreatic and Periampullary Cancer after Adjuvant Chemoradiation or Observation: Long-Term Results of EORTC Trial 40891. Ann. Surg. 2007, 246, 734-740. [CrossRef] [PubMed]

44. Mukherjee, S.; Hurt, C.N.; Bridgewater, J.; Falk, S.; Cummins, S.; Wasan, H.; Crosby, T.; Jephcott, C.; Roy, R.; Radhakrishna, G.; et al. Gemcitabine-Based or Capecitabine-Based Chemoradiotherapy for Locally Advanced Pancreatic Cancer (SCALOP): A Multicentre, Randomised, Phase 2 Trial. Lancet Oncol. 2013, 14, 317-326. [CrossRef]

45. Versteijne, E.; Vogel, J.A.; Besselink, M.G.; Busch, O.R.C.; Wilmink, J.W.; Daams, J.G.; van Eijck, C.H.J.; Groot Koerkamp, B.; Rasch, C.R.N.; van Tienhoven, G.; et al. Meta-Analysis Comparing Upfront Surgery with Neoadjuvant Treatment in Patients with Resectable or Borderline Resectable Pancreatic Cancer. Br. J. Surg. 2018, 105, 946-958. [CrossRef] [PubMed] 